IFN Working Paper No. 921, 2012

\title{
A Reexamination of Renewable Electricity Policy in Sweden
}

Sven-Olof Fridolfsson and Thomas Tangerås 


\title{
A reexamination of renewable electricity policy in Sweden
}

\author{
Sven-Olof Fridolfsson \\ Thomas P. Tangerås* \\ sven-olof.fridolfsson@ifn.se thomas.tangeras@ifn.se \\ Research Institute of Industrial Economics (IFN) \\ Box 55665, 10215 Stockholm, Sweden \\ Telephone: +46 (0)8 66545 00, Fax: +46 (0)8 6654599
}

May 21, 2012

\begin{abstract}
Green certificates are the main instrument for promoting renewable electricity (RES-E) in Sweden. But certificates cover only a limited share of total RES-E production. Under partial coverage, crowding out may arise whereby costly new RES-E replaces inexpensive old RESE. Granting certificates to all of RES-E production improves efficiency, but leaves windfall rent to otherwise profitable facilities. We also analyze transaction costs in the permit process for new RES-E in Sweden. Municipalities veto socially desirable projects because of asymmetrically distributed investment costs and benefits. We propose market-based permit fees rather than limited veto rights as a solution to this NIMBY problem.
\end{abstract}

Keywords: Crowding out, green certificates, NIMBY, transaction costs, windfall rent. JEL Codes: D23, Q48, Q52, Q54.

*Corresponding author. 


\section{Introduction}

Sweden has decided to increase the renewable share of total energy consumption to 50 per cent by 2020. A means to achieve this objective is to promote production of electricity from renewable energy sources (RES-E). The ambition is to expand RES-E production by 17 TWh in 2016 relative to 2002. In comparison, total electricity production was $143 \mathrm{TWh}$ in the baseline year 2002. Green certificates are the main policy instrument for stimulating RES-E in Sweden. ${ }^{1}$ Producers earn one certificate for every MWh certified RES-E they generate. The certificates are sold mainly to retail companies that are obliged to cover a share of final consumption by certified RES-E. Certificates represent an extra source of income in addition to the revenue producers earn on selling the electricity itself, which should stimulate RES-E production; see Section 2 for a description of the Swedish electricity market and its certificate system. We reexamine the Swedish RES-E policy and explore the consequences of $(i)$ a green certificate system which only covers a part of total RES-E production; (ii) transaction costs in the investment decision.

Contrary to many other countries with certificate markets, RES-E accounted for a large share of Swedish production even prior to the introduction of certificates. Hydro power alone stood for 46 per cent of total production in 2002. The certificate market covers only a small share of RES-E production, approximately 15 per cent in 2010. An inefficient crowding out effect arises in certificate markets with partial coverage. Increased production of certified RES-E lowers the electricity wholesale price and renders all types of non-certified production, even renewable, less profitable. As RES-E production from new facilities and capacity expansions is more expensive than old RES-E production - it would not be in need of economic support otherwise - partial coverage leads to inefficient substitution of new for old RES-E.

Crowding out can be relevant even in markets where RES-E production was limited when the certificates were introduced. Many certificate schemes are constrained in the sense that production receives certificates for a shorter period than the economic lifetime of the plant. Certificate supply falls when old plants are phased out of the system. Subsequently, certificate prices increase, which stimulates investment in new capacity. If RES-E production without certificates is unprofitable, then crowding out arises whereby RES-E in new plants replaces

\footnotetext{
${ }^{1}$ Green certificates, or renewable portfolio standards, are now a common policy instrument for promoting RESE production in Europe, the US and beyond (Fischer and Preonas, 2010).
} 
RES-E production in current non-certified plants. Sweden is an interesting case in point. In 2013, 80 per cent of bio-fueled combined heat and power (CHP) capacity loses its right to certificates. These plants stood for more than half of certified RES-E production in Sweden in 2010. The industry predicts RES-E production to fall significantly in plants no longer eligible for certificates.

A simple way to improve efficiency would be to include all RES-E production, old and new, in the certificate system. But full coverage implies windfall rent to RES-E facilities that would have been profitable anyhow. Certificates thus incorporate a trade-off between efficiency and windfall rent.

Crowding out implies that the net potential for renewable electricity is smaller than its gross potential. A reasonable assessment of the net potential for RES-E prior to the introduction of a certificate system increases efficiency and reduces windfall rent. A modest quota obligation lowers certificate demand and the certificate price. With a low certificate price, only the most cost effective investments are undertaken and all renewable electricity earns a lower rent.

In Sweden, all plans to build new power plants must be approved by the local municipality before they can be realized. The industry claims that municipal veto rights, non-transparent decision criteria and long lead times in the decision process represent significant transaction costs which limit investments, especially in onshore wind power. Most of the proceeds of the investment (electricity and certificate revenues) are pocketed by the owners while there can be significant costs (e.g. landscape degradation, noise) to the local community of hosting the power plant. This asymmetric distribution of the investment costs and benefits is the source of the well-known Not In My Backyard (NIMBY) phenomenon whereby local authorities use their political power to block projects they disapprove of. We argue that municipal fees can be an efficient tool for overcoming local resistance to wind power (and other projects). In theory, negotiated fees should internalize the costs and benefits associated with the project and lead to a socially optimal decision. Market-based fees would probably lower transactions costs as the decision criteria become more transparent, and lead times would fall as municipalities now have little to gain from stalling the decisions. Competition for wind power permit fees would limit the exercise of municipal market power and drive the fees down to the competitive level.

Most of the literature assumes that all RES-E production is entitled to certificates and that the rest is non-renewable production (e.g. Amundsen and Mortensen, 2001; Jensen and Skytte, 
2002; Morthorst, 2003; del Río, 2005; Unger and Ahlgren, 2005; Söderholm, 2008; Amundsen and Bergman, 2012). Fischer (2010) allows for partial coverage, but assumes that all non-certified RES-E is large-scale hydro power in constant supply and profitable even absent certificates. Böhringer and Rosendahl (2010) mention in passing that green certificates may lead to reduced supply of renewable electricity not included in the certificate system. None of the above papers discuss efficiency properties related to crowding out or any tradeoffs between efficiency and windfall rent. Nor do they discuss the circumstances under which crowding out is likely to be substantial, or possible solutions to the problem.

Our finding that building permit fees negotiated between investors and municipalities can improve efficiency is just an application of the famous Coase theorem. There are two reasons why we discuss fees. First, Swedish municipalities have in some instances demanded this type of compensation; fees are thus part of an emerging market for wind power projects. Second, these fees are controversial. Critics draw a parallel to corruption and argue against forcing investors to pay municipalities for the permits. From our viewpoint, market-based fees are one way to overcome the NIMBY problem.

\section{The Swedish electricity market and certificate system}

Sweden, Denmark, Finland and Norway form the Nordic electricity market. ${ }^{2}$ A key feature of this market is its reliance on hydro power; see Table 1. Hydro power amounts to half of installed capacity and is located predominantly in Norway and Sweden. Finnish and Swedish nuclear power constitutes ten percent of total generation capacity. Thermal capacity other than nuclear power accounts for roughly thirty percent of capacity, two-thirds of which is CHP. Only Denmark and Sweden have significant amounts of wind power.

Table 1: Generation capacity (GW) in the Nordic market 2010

\begin{tabular}{|l|c|c|c|c|c|}
\hline & Denmark & Finland & Norway & Sweden & Total \\
\hline Hydro & - & 3,1 & 29,9 & 16,2 & 49,2 \\
\hline Nuclear & - & 2,7 & - & 9,1 & 11,8 \\
\hline Other thermal & 9,7 & 10,9 & 1,1 & 8,2 & 29,9 \\
\hline Wind & 3,8 & 0,2 & 0,4 & 2,2 & 6,6 \\
\hline Total & 13,5 & 16,9 & 31,4 & 35,7 & 97,5 \\
\hline
\end{tabular}

Source: NordREG (2011)

\footnotetext{
${ }^{2}$ In addition, the Nordic market is interconnected with Estonia, Germany, Poland, Russia and The Netherlands.
} 
75 per cent of production in the four countries is traded on the common power exchange, Nord Pool. Bilateral contracts between producers, retailers and end consumers make up the rest. More than 200 producers sell their electricity on Nord Pool. No single producer owns more than 20 percent of total generation capacity (NordREG, 2011).

Transmission bottlenecks regularly partition Nord Pool into geographically separate markets, or price areas. Figure 1 shows the average annual (nominal) price in Sweden and some adjacent price areas between 2001 and 2010. System refers to the price that would prevail under full integration, i.e. absent any transmission constraints. The price has increased steadily over the period in all price areas. In Sweden, for example, one MWh electricity cost 2.5 times more in 2010 than 2001. Electricity is more expensive in Sweden than in Southern Norway (price area Oslo), but cheaper than in Denmark East. This means that Sweden imports electricity from Southern Norway, while Southern Norway and Sweden both export electricity to Denmark.

\section{Figure 1: Average annual electricity and certificate prices (Euro/MWh) 2001-2010}



Source: Nord Pool (www.nordpoolspot.com), Svenska Kraftnät (www.svk.se)

Green certificates were introduced in Sweden in 2003 as a support scheme for renewable electricity. The aim is to increase RES-E production in Sweden by 17 TWh in 2016 relative to 2002. Generation companies receive one certificate from the state for each MWh of certified RES-E they produce. Producers sell the certificates to retail companies and to industrial consumers legally bound to cover a share of their consumption by certificates. The revenue from selling the certificates adds to the value of selling the electricity and therefore raises the 
value of investing in renewable electricity production. As Figure 1 shows, certificate prices now represent a significant source of income to producers of renewable electricity and have risen steadily since the introduction in 2003.

Electricity supply can be divided into two groups in a certificate system. Certified production constitutes all renewable electricity generation which has been approved by the authorities to receive certificates. Renewable electricity is produced from peat, biofuels, geothermal-, solarand wave energy, plus hydro power and wind power. Certified production increases can come from new plants, capacity expansions in old plants and decommissioned plants that have been reopened. Non-certified production includes, but is not restricted to, electricity produced from non-renewable sources like fossil fuels or nuclear. Even some renewable electricity falls in this category. The main exemption from the certificate system is large-scale hydro power, which only receives certificates for the part of production stemming from capacity upgrades.

\section{Figure 2: Certificates to new facilities 2004-10}

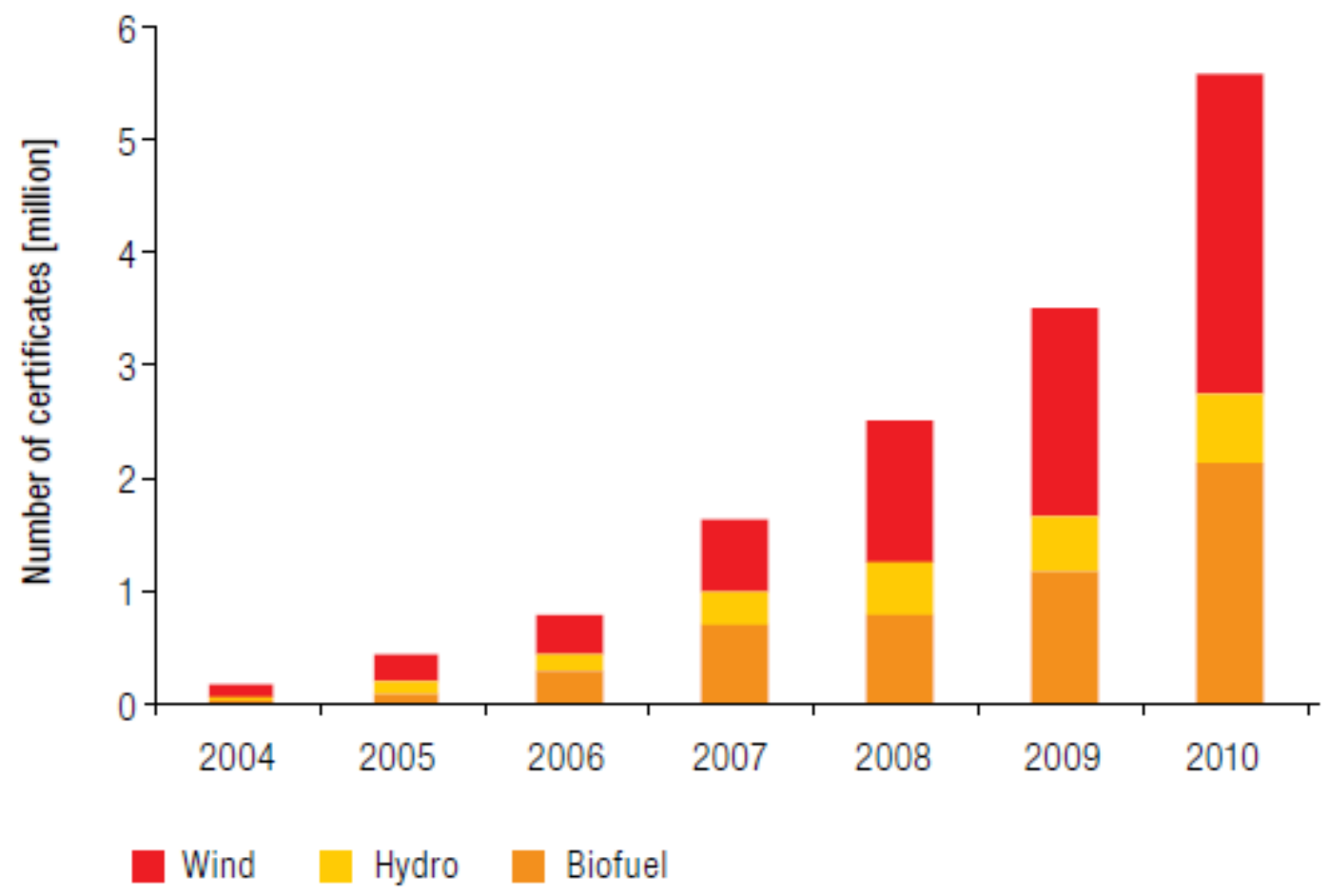

Source: Swedish Energy Agency (2011)

Sweden is well on its way to reaching its $17 \mathrm{TWh}$ target. Certified RES-E production had increased by 11.6 TWh in 2010 relative to the reference year 2002. 1210 new power plants were set into operation during the period and were responsible for $5.6 \mathrm{TWh}$, or close to 50 per 
cent, of the production increase. As Figure 2 illustrates, most of the production in the new facilities is wind power and bio-fueled CHP. The remaining $6 \mathrm{TWh}$ of the production increase were from capacity expansions in old plants and reopened facilities (all numbers are from the Swedish Energy Agency, 2011). An additional 6.5 TWh production available prior to the introduction of the system has been awarded certificates on an annual basis. One reason for including existing production, mostly CHP and small scale hydro power, has been to secure liquidity in the certificate market already from the outset. This production will be phased out of the certificate system from 2013 and onwards.

Judging by the above numbers, the certificate system has been a success in promoting new renewable electricity. But how large share of the production increase can really be attributed to the certificate system? With current price levels as a reference, many of the new facilities would probably not have been built absent an RES-E support scheme. Nyström et al. (2011) estimate the average costs of onshore wind power and bio-fueled CHP at above 60 Euros per MWh. In comparison, the average annual electricity price has not risen above 60 Euros per MWh any single year since 2001; see Figure $1 .^{3}$ Measuring the impact of certificates on production increases in old facilities is more problematic. The cost of expanding capacity in an existing facility or reopening a decommissioned plant is probably substantially lower than the cost building a new facility. Electricity prices more than doubled between 2001 and 2010; see Figure 1. If price increases were anticipated, it is likely that some of the production increases would have happened anyhow. Moreover, producers should only be given certificates for real production increases. Hydro power production fluctuates significantly from year to year depending on rainfall. Benchmark production, which is needed to assess the real magnitude of production increases, is a matter of judgment and based upon information from the producers. Producers are likely to underestimate benchmark production to maximize the allocation of certificates. If so, official data exaggerates production increases in old facilities.

\footnotetext{
${ }^{3}$ Wind, and to a certain extent CHP, are intermittent sources of electricity. Wind power plants only generate electricity and revenue when the wind blows. The average annual electricity price is relevant only if there is no systematic time variation in wind speed. If, for example, the wind is relatively stronger at off-peak hours, a comparison of the average annual electricity price and average cost exaggerates the profitability of wind power; see Joskow (2011) for an illustration of this point. Electricity is produced jointly with heat in CHP plants, and production is higher in winter when heat demand is higher. In Sweden, the electricity price peaks during winter. The profitability of investing in CHP thus is higher than the average annual electricity price seems to suggest.
} 


\section{An economic analysis of RES-E policy in Sweden}

\subsection{Partial coverage of the certificate system}

Figure 3 illustrates the economic consequences of green certificates on electricity production. Production and consumption are on the horizontal axis, while the vertical axis depicts the wholesale price of electricity. To simplify the analysis, assume that demand is insensitive to price and given by $x$. Assume also that the market is competitive. The supply of certified RES-E then is characterized by its marginal cost curve $S_{c}$. The corresponding marginal cost curve of non-certified electricity is $S_{n c}$. Moving (right) left to (left) right in the figure is associated with higher production of (non-)certified electricity. Absent a support system, the market clears at price $p$, where the marginal costs of certified and non-certified electricity are equated. Certified electricity production is $q$ at equilibrium, and the rest of consumption, $x-q$, is covered by non-certified production. Non-certified electricity is supplied by nuclear power and non-certified renewable electricity, like large-scale hydropower, up to the capacity ceiling $x-k$. From thereon, fossil fueled power plants take over. These are coal, gas or oil-fired power plants. Fossil fueled power plants have a relatively high marginal cost, not least due to the cost of emission permits. Hence, only a small part, $k-q$, of equilibrium production stems from fossil fuel sources. Most of electricity production is nuclear or renewable even absent any renewable support scheme.

\section{Figure 3: An electricity market with green certificates}

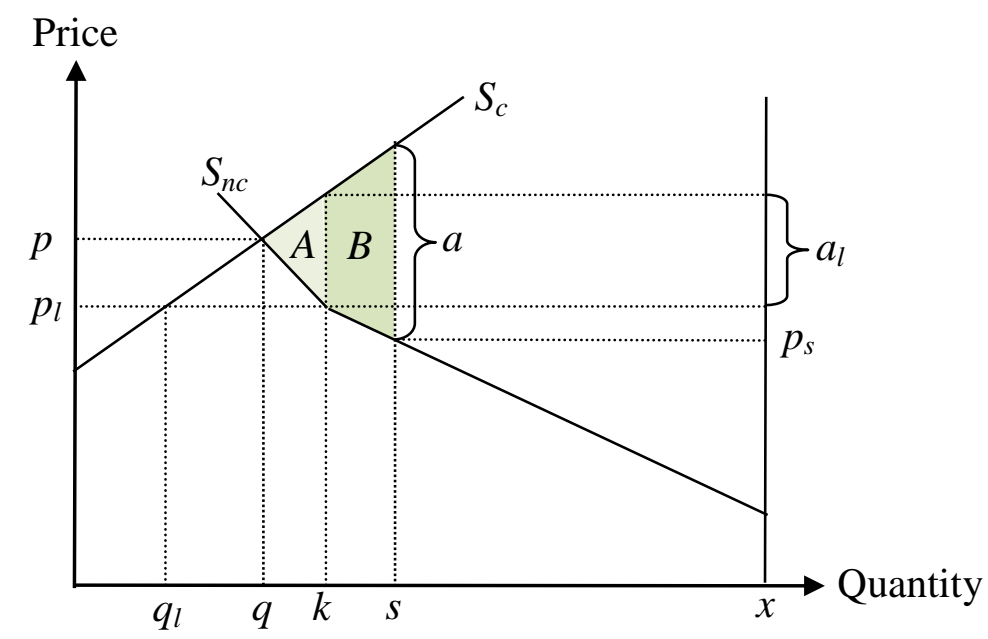

Consider now the introduction of a certificate system with the purpose of increasing certified production from $q$ to $s$, and to lower non-certified production from $x$ - $q$ to $x$-s. To achieve the desired reduction in non-certified production, the electricity price must fall from $p$ to $p_{s}$. For 
certified production of $s$ to be profitable at an electricity price equal to $p_{s}$, the price of the certificate must equal $a$. The owners of certified production gain because of windfall rent $\left(p_{s}+a-p\right) q$ on current production and because of the expansion in production from $q$ to $s$. The producers of non-certified electricity lose because of a windfall loss $\left(p-p_{s}\right)(x-s)$ on current production and due to the output contraction, $s-q$. The effect on consumers is ambiguous. Consumers are now forced to purchase electricity certificates at total cost as. On the other hand, the price of electricity falls from $p$ to $p_{s}$ at a total cost saving of $\left(p-p_{s}\right) x$. The net cost to consumers is $a s-\left(p-p_{s}\right) x$. The introduction of the certificate system is more likely to be costly to consumers if the certificate system is ambitious ( $s$ is large) or the supply of non-certified electricity is price sensitive relative to the supply of certified electricity. In this case it takes a small drop in consumer prices to reduce the output of non-contractible electricity by $s$ - $q$, i.e. $\left(p-p_{s}\right)$ is small, whereas a large certificate price, $a$, is required to increase the production of certified production from $q$ to $s$; see e.g. Fischer (2010). Note also that the net cost of the certificate system varies across consumers. The energy intensive industry is exempted from the quota obligation and therefore benefits from the drop in electricity prices from $p$ to $p_{s}$ without having to pay the certificate price $a$. Some industries reap an additional gain because they are net sellers of certificates. Many pulp- and paper manufacturers in Sweden operate bio-fueled CHP plants in their production process, the electricity production of which is entitled to certificates.

In a competitive market for emission permits, the market price of emission rights reflects the marginal social cost of emissions. Under these conditions, $S_{c}$ and $S_{n c}$ represent the marginal social costs of the different production technologies, even fossil fuel electricity production. Then, the market equilibrium $(p, q)$ is efficient. Introducing certificates on top of an efficient emission trading system creates price distortions which increase the abatement costs of the emission target. In the domestic market the distortion materializes as the replacement of cheap non-certified production by costly certified production. The efficiency loss amounts to the marginal cost difference aggregated over the volume of substituted production, $s-q$, i.e. the sum of the light-coloured triangle $A$ and the darker area $B$ in Figure 3. An additional distortion arises abroad which is not captured in the figure. The price of emission allowances falls in the international market as higher renewable electricity production at home shifts the demand for emission permits downward. The price falls until the market clears and emissions abroad have replaced domestic emissions. The total amount of emissions remains unchanged, as set by the 
target, but expensive fossil production abroad has replaced cheap fossil production at home (Böhringer and Rosendahl, 2010).

In Figure 3, the certificate system is sufficiently ambitious that renewable production entirely replaces fossil production, $k-q$. The corresponding efficiency loss is the area $A$. As the substitution of renewable electricity for non-renewable electricity is an intended effect of the certificate system, the welfare benefits elsewhere presumably outweigh the inefficiency $A$. The efficiency loss $B$ arises as a consequence of certified renewable electricity replacing other climate neutral electricity such as non-certified RES-E and nuclear power (actually, nuclear power does emit small amounts of greenhouse gases). Certificates thus suffer a crowding out effect whereby expensive non-emitting electricity replaces cheap non-emitting electricity. ${ }^{4}$ Substituting renewable energy for nuclear power could improve welfare insofar as nuclear power fails to carry its full environmental cost, although it would be more efficient to correct this distortion by a directed measure, for instance a tax on nuclear production. Justifying why some production of renewable electricity should be subsidized to replace other renewable electricity is much more difficult.

Observation 1: In a certificate system with partial coverage, inefficient crowding out arises whereby costly new RES-E replaces old inexpensive RES-E production.

Crowding out of renewable electricity is likely to be more substantial the larger was RES-E production prior to the introduction of certificates and the smaller the share of total renewable production covered by the certificate system. Sweden has always relied heavily on renewable electricity. In 2002, the year before the introduction of the certificate system, hydro power alone amounted to $65.8 \mathrm{TWh}$, or 46 per cent, of total Swedish electricity production. ${ }^{5}$ Only 11 TWh certificates were issued in 2004, the first full year of the certificate system, 7.7 TWh of which went to bio-fueled CHP (Swedish Energy Agency, 2011). The certificate system thus covered around 15 per cent of total renewable electricity production at the outset. In spite of its limited coverage, crowding out may not have been much of a problem during the first years of the certificate system. Most non-certified RES-E was large scale hydro power which most likely was profitable even at low prices, i.e. contained in the $x$-s domain in Figure 3. Crowding out is likely to become more prevalent in the future. Historically, the largest share

\footnotetext{
${ }^{4}$ Crowding out is a side effect shared by all subsidization schemes for renewable electricity because they drive down the wholesale price of electricity and render some alternative production unprofitable.

${ }^{5}$ Retrieved from www.scb.se/Pages/TableAndChart_24271.aspx, May 13, 2012.
} 
of certified renewable electricity has come from CHP plants, 60 per cent in 2010. In 2013, 80 per cent of this capacity will be phased out of the certificate system (Swedish Energy Agency, 2011). Bio-fueled CHP plants are not necessarily competitive absent certificates, so there is a real risk of a significant proportion of renewable electricity produced in these plants vanishing after 2012. A negative supply shock in the certificate market transfers into a higher certificate price which stimulates investment in new renewable electricity. We then have a situation much similar to the one depicted in Figure 3 whereby expensive new renewable electricity replaces inexpensive old renewable electricity. In a survey about their anticipations of the imminent change to the certificate system, owners of CHP plants revealed plans to decommission plants or reduce production in old facilities in the magnitude of $1.5 \mathrm{TWh}$ renewable electricity (Svensk Energi, 2011). The same owners intended to invest some 3.7 billion Euros in new plants with an annual production of 5.1 TWh certified renewable electricity. The net increase is $3.6 \mathrm{TWh}$, implying a crowding out of 30 per cent. Actual crowding out might even be larger. Fuel expenses represent a significant part of the operating cost of CHP plants. Waste is a particularly cheap fuel compared to biofuels. Indeed, the fuel cost is negative because CHP plants are paid by their suppliers to accept the waste. Some old CHP plants will probably switch to waste incineration once phased out of the certificate system, unless plant conversion is prohibitively expensive. As the renewable content of waste is lower than in biofuels, some substitution of non-renewable fuels for biofuels is likely to occur.

Norway introduced a certificate system similar to the Swedish in 2012. As can be seen from Table 1, Norway's electricity supply is already almost fully renewable: 95 per cent of capacity was hydro power in 2010. If electricity consumption is constant, then a certificate system cannot possibly have any net effect on renewable electricity production. Crowding out could even exceed 100 per cent. Instead of constant demand, make the more realistic assumption that demand falls as the retail price of electricity, $p+a f$, increases, where $p$ is the spot price of electricity, $a$ is the certificate price, and $f$ is the quota obligation (we abstract from VAT and other taxes). Both $p$ and $a$ depend on $f$ at equilibrium. If the obligation $f$ is substantial or the supply of non-certified electricity is price sensitive relative to certified electricity, the retail price of electricity increases with the introduction of certificates. Consumption and aggregate production fall in response. Since all production was renewable from the start, total renewable production by necessity must fall. The certificate system then has the bizarre consequence of 
reducing renewable electricity production. ${ }^{6}$ A net loss in renewable electricity is probably not what policy makers envision when introducing green certificates.

Green certificates are designed with the purpose of being technology neutral: What matters is the generation of renewable electricity, not the energy source used to produce it. In light of the above discussion it is relevant to ask whether the current design of the certificate system really serves its intention in this respect. In Sweden, new facilities cannot receive certificates for more than 15 years and certainly not beyond 2035. The question is what happens to RESE production after the facility has been phased out of the system. Most of the investments have been in wind power and bio-fueled CHP; see Figure 2. Wind-, hydro- and solar power have low short-run marginal production costs and are profitable to operate even after the allocation of certificates has ended. These facilities mainly need financial support to cover the initial capital costs of the investment. CHP plants have a relatively high short-run marginal production cost and need support to cover renewable fuel cost. CHP plants built to support waste incineration will probably discontinue production of renewable electricity once the support period has ended. Hence, a time limited certificate system is not necessarily technology neutral across the entire life span of the plant.

Several steps can be taken to reduce the negative consequences of the certificate system. The first is to make a reasonable assessment of the potential of the certificate system before setting the quota obligation. Reconsider Figure 3 and assume that the entire non-certified capacity $x-k$ is renewable electricity. The upper bound to additional RES-E is then $k-q$, no matter how many subsidies are poured into the system. A quota obligation of $k / x<s / x$ is sufficient to capture the full potential of renewable electricity. To achieve this less ambitious target, the electricity price only has to fall to $p_{l}>p_{s}$, and the corresponding certificate price is lower: $a_{l}<a$. No renewable electricity is crowded out and the efficiency loss is smaller, i.e. $B$ vanishes. Windfall rent is lower owing to a lower certificate price. It can be reduced even further by only including the $k-q_{l}$ MWh renewable electricity that would not be profitable without support. This is renewable electricity with marginal costs in the range between $p_{l}$ and $p_{l}+a_{l}$. Additional rent savings could be achieved by paying certificate prices differentiated according to marginal cost instead of a uniform price for all certified electricity.

\footnotetext{
${ }^{6}$ Amundsen and Mortensen (2001) show that even the supply of certified RES-E can fall as the quota obligation increases.
} 
Creating an RES-E support scheme which avoids crowding out and simultaneously minimizes windfall rent to RES-E production is demanding in terms of the information necessary to implement it. Most importantly, the policy maker would need to know the investments costs of renewable electricity and also be able to separate cost efficient facilities from the ones in need of support. One solution to the problem of crowding out is to include all renewable electricity in the certificate system. Full coverage is more efficient as it avoids the substitution of expensive new renewable electricity for cheap old renewable electricity. The equilibrium certificate price is lower, and the same (or higher) net investment is achieved as under partial coverage because no efficient renewable electricity facility is excluded from the certificate system under full coverage. The effect on windfall rent is ambiguous. Consider Figure 3 and maintain the assumption that the capacity $x-k$ is renewable electricity. Under full coverage, net investment $k-q$ is achieved at a lower certificate price $a_{l}<a$, which tends to reduce windfall rent. On the other hand, a larger share of production receives certificates under full coverage: $q+x-k>q$. Windfall rent is higher under full coverage if either capacity, $x-k$, is large or has relatively low marginal cost. In this second case, the price difference $p_{s}+a-p_{l}-a_{l}$ is small.

Observation 2: There is a general trade-off between efficiency and windfall rent under green certificates.

An alternative approach to subsidizing renewables would be to tax fossil fuels. In Figure 3, a carbon tax shifts the fossil fuel part of the $S_{n c}$ curve upwards, i.e. the part to the left of $k$. The tax raises the price of electricity and increases production of non-fossil fueled electricity. The tax does not have to be particularly fine-tuned. Any carbon tax above $a_{l}$ renders fossil fueled electricity unprofitable. The market price of electricity increases from $p$ to $p_{l}+a_{l}$ to clear the market. Obviously, a carbon tax has no effect if there is no fossil fuel electricity production. Therefore, renewables can increase at most by $k-q$ under the carbon tax. Hence, there is no crowding out of renewable electricity under a carbon tax. The carbon tax has a number of drawbacks as a tool for renewable investment. It is imprecise as it spurs investment in all types of production, even nuclear power, and not only renewables. Electricity is also more expensive under the carbon tax than with green certificates because it drives up the wholesale price of electricity. In an efficient certificate system, the retail price is $p_{l}+f a_{l}$, where $f$ is the quota obligation. The corresponding retail price under the carbon tax is $p_{l}+a_{l}$. A carbon tax thus generates a larger windfall rent than an efficient certificate system. A main difference between green certificates and carbon taxes is the effect on the energy intensive industry. The industry benefits from certificates because they drive down the electricity wholesale price. 
Taxes are costly, even if the industry actually does not have to pay them, due to the adverse effect on the wholesale price of electricity. The advantages to the energy intensive industry are probably one explanation why policy makers prefer subsidies to taxes.

\subsection{Transaction costs}

In Sweden, all plans to build new power plants must be approved by the local municipality before they can be realized. The municipality does not have to motivate its decision, and it is unclear whether rejections can be appealed. The industry claims municipal veto rights, nontransparent decision criteria and long lead times in the decision process to present major obstacles to RES-E investment, particularly for onshore wind power (Energimyndigheten, 2009). Söderholm (2008) argues that these transaction costs give Sweden a competitive disadvantage in renewable electricity compared to neighboring countries.

\section{Figure 4 Municipal veto rights}

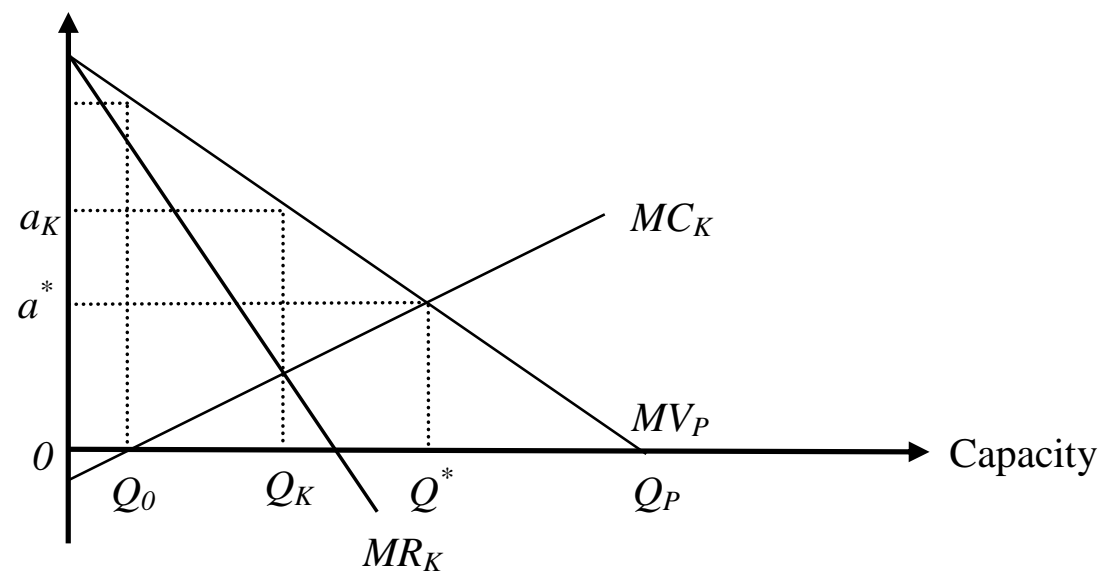

Figure 4 illustrates potential problems associated with municipal veto rights. The $M V_{P}$ curve represents the marginal value of wind power as perceived by investors. This value is determined by the expected wholesale and certificate revenues, less investment and operating costs. The sites with optimal wind conditions in relation to the construction cost are utilized first. Hence, the marginal value of wind power is decreasing in capacity. Investors free to decide on the amount of wind power would build new capacity in the municipality until the point at which the marginal value was zero, at $Q_{P}$ in the figure. The $M C_{K}$ curve reflects the marginal cost of wind power as perceived by the municipality. It includes local environmental costs, such as noise. The municipality may also expect less tourism as a consequence of visual depreciation of landscape and environment. All wind power in excess of $Q_{0}$ is costly to the 
municipality and would be vetoed. A positive share $Q_{0}>0$ is permitted due to local benefits, for example positive local employment effects. The socially optimal amount of wind power is found at $Q^{*}$, where marginal value equals marginal cost. Municipal veto rights yield underinvestment $\left(Q_{0}<Q^{*}\right)$ insofar as the municipality fails to take sufficient account of the marginal value of wind power. The free entry equilibrium yields overinvestment $\left(Q_{P}>Q^{*}\right)$ because the investors do not internalize the local costs of wind power.

One proposed solution to the underinvestment problem has been to abolish municipal veto rights and replace it by a centralized decision procedure which grants construction permits based upon the arguments presented by the interested parties. As the socially optimal capacity $Q^{*}$ is contained in the interval $Q_{0}$ to $Q_{P}$, a simple solution would be to grant permits in the average between the investors' demands and the municipal concessions, $\left(Q_{0}+Q_{P}\right) / 2$. But decision criteria like this give the municipality an incentive to exaggerate the cost and the investors to exaggerate the benefit of new wind power. A centralized decision process thus runs the risk of revealing preciously little about the net value of wind power projects.

Municipalities have in some instances demanded compensation from investors for granting permission to construct wind power plants. Critics draw a parallel to corruption and argue that investors should not be forced to pay municipalities for the permits. But according to the Coase theorem, municipality and investors would negotiate a socially optimal fee if property rights were appropriately assigned. The negotiation would internalize the costs and benefits of the project and the outcome maximize total welfare. A fee equal to $a^{*}$ in Figure 4 lowers the investors' valuation and boosts the municipality's benefit of wind power precisely to the point at which demand for and supply of wind power licenses equal $Q^{*}$.

A market-based permit system has the obvious advantage of decentralized decision making. The socially optimal fee varies between locations depending on wind conditions, plant size, capacity, costs of connecting the plant to the grid, population density, environmental costs, and more. A cost efficient centralized process would be streamlined and apply uniform decision criteria which cannot fully account for project idiosyncrasies. Market-based permits are transparent: Either the investor and municipality negotiate an acceptable fee, or the construction application is rejected. Furthermore, lead times are expected to fall because the municipalities no longer have much to gain from stalling the decision process. In summary, transaction costs probably are lower under the market-based permit system. 
Observation 3: Maintaining municipal veto rights and allowing municipalities and investors to negotiate construction permit fees might improve the efficiency of RES-E investments.

Municipal fees suffer from a number of drawbacks. Efficiency requires local policy makers to maximize expected municipal utility, which is not necessarily the case. Fees represent a source of municipal income which may tempt politicians to override local concerns, in particular if environmental costs are concentrated to a minority of politically marginalized inhabitants. By understating local costs, politicians bias their decisions in favor of investment. Even the opposite is possible; that local environmental groups exercise too much political influence, resulting in underinvestment. Legally binding standards, such as a requirement that wind power plants should have a minimum distance to residential buildings, provide minimal protection to the members of the municipality and thus represent a valuable supplement to market-based negotiations.

The Coase theorem relies on the assumption that all parties are perfectly informed about all costs and benefits of the project. This informational requirement is unlikely to be fulfilled in reality. Based upon experience with other projects, data about wind conditions, and so forth, it is possible for outsiders to assess the expected market value of a specific wind power project. However, it is probably difficult for outsiders to assess the perceived municipal marginal cost of the project. Municipal representatives possess an informational advantage over investors which can be used to their own advantage in the negotiation. By exaggerating the municipal marginal cost above $M C_{K}$, negotiators can raise the fee above the competitive level, $a^{*}$. The optimal fee, $a_{K}$, from the viewpoint of the municipality, is found at the capacity $Q_{K}$ where marginal revenue, $M R_{K}$, equals marginal cost, $M C_{K}$. Municipal market power thus leads to underinvestment $\left(Q_{K}<Q^{*}\right)$, although the problem is smaller than was the case with municipal veto rights, but absent any fees $\left(Q_{0}<Q_{K}\right)$.

Municipal market power is limited insofar as prospective wind power sites are available to investors in more than one municipality. Wind power plants generate municipal revenue if investors are forced to pay construction fees. This opens a market for wind power projects whereby municipalities compete against each other to attract the best projects. Competition drives down municipal fees and delivers a number of efficiency gains. First of all, resources are allocated to the projects with the largest net benefit. Second, lower fees reduce transaction costs, and improve the competitiveness of Swedish wind power projects. 
Figure 5: Municipal competition for wind power projects

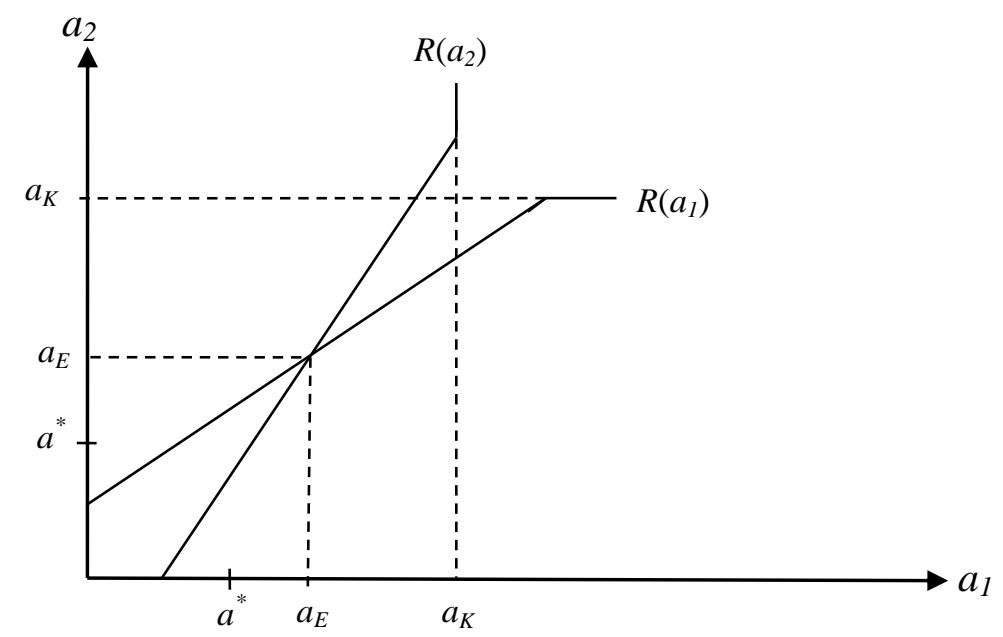

Figure 5 illustrates the effect of municipal competition on investment. Assume that there are two municipalities and that projects are substitutes from the viewpoint of the investors. To simplify exposition, we even assume that the municipalities are symmetric. The $R\left(a_{2}\right)$ curve returns the optimal fee chosen by municipality 1 as a function of the fee, $a_{2}$, in municipality 2 . The higher is the fee in municipality 2 , the higher is demand for projects in municipality 1 . Increased demand makes it profitable to increase the fee in municipality 1 , and so $R\left(a_{2}\right)$ is increasing in $a_{2}$. All projects in municipality 2 are unprofitable if $a_{2}$ is too high. In this case, municipality 1 optimally charges the monopoly fee, $a_{K}$. Correspondingly, $R\left(a_{1}\right)$ depicts the optimal fee in municipality 2 as a function of the fee, $a_{l}$, in municipality 1 . The equilibrium fee is found at $a_{E}$ where no municipality profits from changing its fee given the fee chosen by the competing municipality. Municipal competition drives down the equilibrium fee below the monopoly level $\left(a_{E}<a_{K}\right)$, although the fee still exceeds the socially optimal level $\left(a_{E}>a^{*}\right)$. Lower fees reduce the underinvestment problem $\left(Q_{E}>Q_{K}\right)$, but does not eliminate it $\left(Q_{E}<Q^{*}\right)$. But as competition is intensified, the equilibrium fee and investments are driven closer and closer to the competitive outcomes $a^{*}$ and $Q^{*}$.

Currently, most of the proceeds of the investment are pocketed by the owners while there can be significant costs to the local community of hosting the power plant. The asymmetric distribution of costs and benefits leads to NIMBY reasoning whereby local authorities block undesirable (for them) projects by municipal veto. Municipal building permit fees could lead to more efficient investment as well as a more transparent licensing process. But this is just one way to increase local approval and avoid NIMBY. The key is to share the benefits of the project with the members of the local community. Another solution is local ownership. Wind 
power plants owned by local cooperatives are quite common in Sweden and may explain why a significant number of wind power plants have been built even under municipal veto rights.

\section{Conclusion}

We have extended the economic analysis of green certificates to allow for partial system coverage and investment transaction costs. In a certificate system which covers only a share of total renewable electricity production, inefficient crowding out arises whereby costly new renewable electricity replaces inexpensive old renewable electricity. An example of crowding out is when power plants phased out of the support system are decommissioned and replaced by new, certified plants. Bio-fueled CHP amounted to 60 per cent of Swedish certified renewable electricity production in 2010 . In 2013,80 per cent of this capacity will lose the right to obtain certificates. With access to plant level data one could shed more light on the important relationship between green certificates and renewable electricity production.

Asymmetrically distributed investment costs and benefits lead local municipalities to veto socially desirable projects. We propose market-based permit fees rather than limited veto rights as a solution to this problem.

\section{Acknowledgements}

We are grateful to Magnus Allgulin, Björn Carlén, Maria Sunér Fleming, Yvonne Fredriksson, Peter Frykbom, Lennart Hjalmarsson, Pär Holmberg, Kjell Jansson, Gunnar Lundberg, Johannes Mauritzen, Magnus Torstensson and Patrik Söderholm for their comments on a previous version of this paper. This research was financed within the IFN research program "The Economics of Electricity Markets".

\section{References}

Amundsen, Eirik S. and Lars Bergman (2012): Green certificates and market power on the Nordic power market, Energy Journal 33, 101-117.

Amundsen, Eirik S. and Jørgen Birk Mortensen (2001): The Danish green certificate system: Some simple analytical results, Energy Economics 23, 489-509.

Böhringer, Christoph and Knut Einar Rosendahl (2010): Green promotes the dirtiest: On the interaction between black and green quotas in energy markets, Journal of Regulatory Economics 37, 316-325.

Energimyndigheten (2009): Konsekvenser för elkunden av en höjd ambitionsnivå i elcertifikatsystemet, ER 2009:35. 
Fischer, Carolyn (2010): Renewable portfolio standards: When do they lower prices? Energy Journal 31, 101-119.

Fischer, Carolyn and Louis Preonas (2010): Combining policies for renewable energy: Is the whole less than the sum of its parts? International Review of Environmental and Resource Economics 4, 51-92.

Jensen, Stine G. and Klaus Skytte (2002): Interactions between the power and green certificate markets, Energy Policy 30, 425-435.

Joskow, Paul (2011): Comparing the costs of intermittent and dispatchable electricity generating technologies, American Economic Review Papers \& Proceedings 101, 238-241.

Morthorst, Poul E. (2003): A green certificate market combined with a liberalised power market, Energy Policy 31, 1393-1402.

NordREG (2011): Nordic market report, Report 3/2011.

Nyström, Olle, Per-Axel Nilsson, Clas Ekström, Anna-Maria Wiberg, Bengt Ridell and David Vinberg (2011): El från nya och framtida anläggningar 2011, Elforsk rapport 11:26.

del Río, Pablo (2005): A European-wide harmonised tradable green certificate scheme for renewable electricity: Is it really so beneficial? Energy Policy 33, 1239-1250.

Svensk Energi (2011): Sveriges utbyggnad av kraftvärme till 2020 - med fokus på elcertifikatsystemets effekter, Retrieved from www.svenskenergi.se April 18, 2012.

Swedish Energy Agency (2011): The electricity certificate system 2011, ET2011:52.

Söderholm, Patrik (2008): The political economy of international green certificate markets, Energy Policy 36, 2051-2062.

Unger, Thomas and Erik O. Ahlgren (2005): Impacts of a common green certificate market on electricity and CO2-emission markets in the Nordic countries, Energy Policy 33, 2152-2163. 